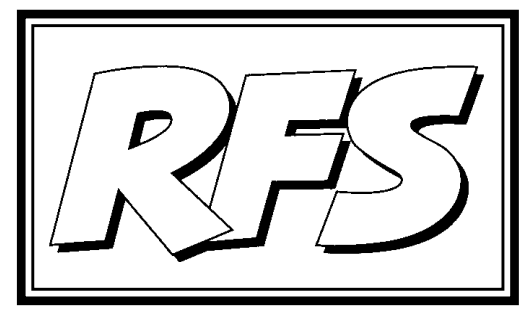

Revista de Fomento Social, 61 (2006), 139-164

\title{
La financiación de la Unión Europea: los límites de una ambición
}

\author{
(Palabras clave: Unión Europea, Presupuestos, Perspectivas FNancieras \\ KEY WORDS: EuROPEAN UNION, BudGET, FinANCIAL PERSPECTIVES)
}

\section{Introducción}

A la hora de redactar estas líneas, la larga y difícil negociación sobre el sistema de financiación de la UE en el periodo 2007-2013 ha desembocado en un resultado definitivo, habiéndose llegado el 15 de mayo de 2006 al acuerdo del triángulo Comisión-Consejo-Parlamento, mediante la aprobación porparte del Consejo de Ministros de Asuntos Exteriores y, la firma posterior, del llamado "Acuerdo interinstitucional", en Estrasburgo, el 17 de mayo.

1 Agradecemos a nuestros colegas los profesores $M^{\mathrm{a}}$ Luz Ortega Carpio y Gabriel $\mathrm{M}^{\mathrm{a}}$ Pérez Alcalá sus valiosas observaciones a una versión preliminar del presente texto. 
La tesis que defendemos en el presente artículo es que los volúmenes financieros previstos en el documento aprobado no responden a las necesidades del actual momento de la construcción europea ni a la lógica de ésta. Tanto la reciente ampliación como los relativamente ambiciosos planteamientos de la Constitución Europea (Proyecto de Tratado por el que se establece una Constitución Europea), aparcada de momento ${ }^{2}$, son mucho más coherentes con las intuiciones y los valores que animaron a la Unión Europea desde sus orígenes. Pero todo esto tiene un coste, también económico, para el que parece faltar en estos momentos la voluntad política de los gobiernos de los países miembros. Esta falta de voluntad es la que revelan los agrios debates a que hemos asistido recientemente hasta llegar a las previsiones presupuestarias aprobadas y que queremos examinar en estas páginas.

Si defendimos en un reciente artículo editorial el sí a la Constitución Europea ${ }^{3}$, era porque sintonizábamos con la idea de avanzar en la construcción de Europa con pasos decididos. Lo hicimos sin ignorar que dicho proyecto encerraba limitaciones y era perfectible. No extrañará que ahora reaccionemos con cierta sorpresa ante la "tacañería" que inspira estas previsiones presupuestarias, y que nos preguntemos si no hubiera sido preferible decidir sobre la última ampliación simultáneamente con la disponibilidad de los Estados miembros para suministrarfondos a los presupuestos comunitarios. Al menos se hubiera evitado esa especie de contradicción en que nos encontramos ahora. Si la ampliación pudo ser entendida como un gesto muy en concordancia con la dinámica de la Unión Europea, la situación actual parece un frenazo en ese camino, frenazo que se confirma con la incertidumbre que rodea al futuro del proyecto de Constitución. En todo caso, parecería un contrasentido dar luz verde a ese proyecto políticamente ambicioso a la vez que se reducen drásticamente los medios financieros necesarios o convenientes para su efectiva implementación.

La convergencia de estos tres hechos -ampliación, parón a la Constitución europea y previsiones presupuestarias- es lo que sirve de trasfondo a este

2 El proceso de ratificación no se ha detenido; el último país en ratificarlo ha sido Estonia, el 9 de mayo, mediante votación parlamentaria. A estas fechas (mayo 2006) son ya 15 los países que lo han ratificado (Alemania, Austria, Bélgica, Chipre, Eslovaquia, Eslovenia, España, Estonia, Grecia, Hungría, Italia, Letonia, Lituania, Luxemburgo y Malta); 2 lo han rechazado por referéndum (Francia y Países Bajos) y 8 están pendientes de ratificación (Dinamarca, Finlandia, Irlanda, Polonia, Portugal, Reino Unido, República Checa y Suecia).

3 Véase Consejo de Redacción (2006), "Más allá de la Constitución: Europa entre las raíces cristianas y la laicidad": Revista de Fomento Social, nº 236, octubre-diciembre, pp. 727-749. 
editorial. Pero daremos prioridad en nuestras reflexiones a este último punto. Como en otras ocasiones, tendremos que prescindir de algunas cuestiones complementarias, en un tema tan complejo como es el de la financiación de la UE, y nos limitaremos a aportar aquellos elementos informativos que nos parecen ineludibles para comprender lo que está en juego en este debate.

A los efectos de este texto utilizaremos la expresión "presupuesto", sin más, para referirnos a la planificación financiera de la UE para un año determinado; por el contrario, se suelen usar las expresiones "perspectivas financieras", "previsiones financieras" o "marco financiero plurianual" para los documentos presupuestarios referidos a un periodo de varios años, normalmente de siete; precisamente el que acaba de aprobarse abarca el periodo 2007-2013.

Hemos estructurado el texto de la siguiente forma: comenzamos por una breve explicación de lo que ha sido el sistema presupuestario de la Comunidad hasta 2006. Luego ofrecemos a los lectores una síntesis acerca de las previsiones financieras para el siguiente periodo de programación; para ello, nos ha parecido que lo más conveniente es seguir el itinerario temporal del proyecto hasta su aprobación definitiva, lo que permite poner de relieve las dialécticas que se han enfrentado con esta ocasión. En el apartado 4 resumimos las razones de fondo de la polémica presupuestaria. Terminamos invitando a hacer una reflexión sobre algunos aspectos que están en juego y sobre los retos que se plantean al proyecto europeo en relación con esta cuestión.

\section{Los presupuestos de la UE}

Cuando nos referimos a los presupuestos comunes de la Unión estamos hablando de un volumen financiero que supera actualmente los 110.000 millones de euros, lo que representa en torno al $1 \%$ del Producto Nacional Bruto agregado de la UE, unos 250 euros por habitante. No cabe duda de que se trata de una gran cantidad de dinero en términos absolutos, pero muy reducida en términos relativos, si se tiene en cuenta que los volúmenes de gasto público nacional representan casi la mitad del ingreso de los Estados más desarrollados. Es cierto que las competencias comunitarias son reducidas en comparación con las que se reservan los Estados nacionales, pero resulta difícil valorar como excesivo ese $1 \%$ a la vista de la importancia histórica, económica y política del proyecto europeo. Aun así, uno de los grandes debates en curso se debe a que no pocos países, especialmente los que más aportan al presupuesto común, consideran excesiva su aportación, estimada según el sistema que veremos a continuación. 


\subsection{El procedimiento presupuestario}

La UE elabora anualmente sus presupuestos siguiendo un procedimiento que hace intervenir principalmente a tres instituciones, aparte de los órganos consultivos: la Comisión, encargada de presentar la propuesta, el Consejo y el Parlamento. Sin entrar en detalles que alargarían excesivamente el texto, recordemos que la Comisión elabora un primer borrador siguiendo unos criterios definidos yen el marco de los presupuestos plurianuales llamados "perspectivas financieras" elaborados para 7 años 4 . Consejo y Parlamento proceden a una serie de lecturas sucesivas de los borradores hasta llegar a un consenso; la última palabra acerca de los llamados "gastos obligatorios" la tiene el Consejo; pero acerca de los "gastos no-obligatorios" el Parlamento tiene poder de veto, especialmente a partir del aumento de sus poderes que le otorgaba el Acta Única Europea (AUE); es preciso llegar a un acuerdo sobre estos capítulos para que los presupuestos queden aprobados en su totalidad.

Además, el presupuesto es siempre equilibrado, nunca hay déficit; esta aparente excepcionalidad del presupuesto comunitario (sobre todo en comparación con los presupuestos de la mayoría de los Estados miembros) tiene una explicación bien simple: primero se aprueban los gastos, siguiendo el procedimiento indicado y, a continuación, de manera automática, se estima el volumen de las contribuciones de cada país a dicho presupuesto, siguiendo un sistema que está detalladamente establecido. De esa forma, obviamente, nunca se producen déficits, además hay ciertas cantidades para imprevistos $y$, por otra parte, cuando se aprueban los gastos, cada país conoce inmediatamente cuál será su aportación para el ejercicio presupuestario correspondiente.

4 El marco presupuestario (o perspectivas financieras) vigente comprende el periodo 2000-2006 y está a punto de concluir. Volveremos sobre ello más adelante.

5 El sistema de determinación del presupuesto comunitario distingue entre gastos obligatorios y no obligatorios. En un primer momento, es decir antes del AUE, los gastos obligatorios eran aquellos en los que había que incurrir porque estaban recogidos en el tratado de Roma (por ejemplo, la Política agraria). Cuando se aprueba el tratado del AUE, algunos gastos, hasta ese momento no obligatorios, debieron ser considerados obligatorios puesto que ya estaban recogidos en un tratado, por ejemplo la política regional. No obstante, se decide seguir llamando a estos gastos no obligatorios, para que la última palabra sobre ellos la tenga el Parlamento. Éste planteamiento ha aumentado el poder del Parlamento en el proceso de toma de decisiones, puesto que la política regional y las políticas comunes emanan del AUE y son consideradas gastos no obligatorios. Por lo tanto, la definición de gastos obligatorios que son aquellos que emanan del tratado de Roma y gastos no obligatorios los que emanan de otros tratados. 


\subsection{El sistema tradicional de ingresos}

Una vez conocido el volumen total de gastos, el cálculo de las aportaciones de cada Estado miembro se hace de la siguiente forma.

- Se estima el total aproximado de ingresos que se producirán a lo largo del año por el concepto de los llamados "recursos propios tradicionales" (básicamente constituidos por los aranceles netos ${ }^{6}$ percibidos en las aduanas exteriores de la UE, incluidos los generados por las importaciones agrícolas); esta es una cantidad decreciente, que actualmente sólo cubre en torno al 11,5\% de los gastos.

- A continuación, siguiendo un sistema iniciado en 1983, se aplica un porcentaje sobre la base imponible común armonizada del IVA de cada Estado miembro; este porcentaje es del 0,5\% en 2006 y viene descendiendo desde el 1,4\% en que estuvo establecido de 1986 a 1994; por tanto, el volumen de fondos por este recurso ha ido decreciendo, representando en la actualidad algo más del 14\% de los gastos.

- Por último, la cantidad que resta a cubrir se distribuye proporcionalmente entre los Estados miembros según el criterio de su renta nacional bruta. Al tratarse de una partida calculada por diferencia, su importancia absoluta y relativa ha ido creciendo a medida que disminuía el recurso IVA, cubriendo en la actualidad en torno al 73\% de los gastos totales de la UE.

De esta forma, se produce un reparto aproximadamente equitativo, según el cual cada país aporta en proporción a su nivel relativo de renta. Sin embargo, este sistema vigente hasta la fecha, que es el resultado de un proceso histórico complejo, no ha estado exento de problemas y, como veremos, el debate acerca de un nuevo método de cálculo del reparto está en su apogeo y sujeto a fuertes polémicas.

6 Dado que estamos en una Unión Aduanera y, más aún, en un Mercado Único, los aranceles son recursos de la UE, no de los Estados donde se recaudan. Puesto que no existe una administración aduanera comunitaria, sino que cada país utiliza su propia administración para recaudar los aranceles diversos en frontera, los países donde se encuentran las aduanas tienen derecho a retener un $25 \%$ de los ingresos arancelarios brutos en concepto de gastos de recaudación.

7 Se trata de unos montantes globales estimados por los servicios de la Comisión, a partir de las estadísticas nacionales de la masa de bienes y servicios imponibles por el IVA, homogeneizando con criterios comunes las partidas comprendidas en dicha base imponible en los distintos países. No es, por tanto, un porcentaje sobre la cantidad total recaudada por IVA en dichos Estados miembros, como, por error, con frecuencia se cree. 


\subsection{El destino de los gastos}

¿En qué se gasta el dinero común la UE? Todo ese volumen de ingresos recaudados, alrededor de 100.000 millones de euros, según hemos indicado, se gastó de la siguiente forma, en el presupuesto de 2005 (por orden de magnitud)

- $42,6 \%$ de los gastos se destinaron a la protección a la agricultura, en sus diversas formas, pero sobre todo a la protección de precios y mercados (principalmente lo que corresponde al fondo FEOGA ${ }^{9}$ - Sección Garantía).

- Viene a continuación el amplio paquete de medidas de tipo estructural, de políticas de cohesión interterritorial o política regional, que absorbieron el 36,4\% de los recursos. Por tanto, sólo estas dos políticas sectoriales representaron cerca del $80 \%$ de los gastos comunitarios. Ninguna otra Unión Aduanera (y, no digamos, Zona de Libre Comercio) del mundo aplica recursos a este tipo de políticas.

- Las llamadas "políticas internas" (todas las políticas que no sean ni la PAC, ni la política regional: es decir, la medioambiental, de investigación, etc.) absorbieron en torno a 7,8\% del presupuesto.

- Las "acciones exteriores", como se denomina básicamente a la cooperación al desarrollo de la UE (aparte de la de los Estados miembros) representaron el $4,5 \%$.

- Los gastos administrativos (incluido todo el complejo aparato institucional europea) ascendieron a un 5,4\%.

- El resto se dedicó a reservas, a ayudas a los países que esperan el momento de la adhesión, y a las llamadas compensaciones temporales a los nuevos países miembros recientemente incorporados.

8 Las cifras para un mismo año pueden sufrir ligeras modificaciones; para empezar, existen, por así decirlo, dos tipos de contabilidad: la de gastos (créditos de compromiso) y la de pagos (créditos de pago) que nunca coinciden aunque son parecidas. Asimismo pueden existir ligeras desviaciones entre el presupuesto y el gasto final consolidado al cierre del ejercicio contable. No podemos entrar en todos estos detalles.

9 Fondo Europeo de Orientación y Garantía Agrícola. Para el periodo de programación 2007-2013 se crea un fondo específico para el Desarrollo Rural (llamado el segundo pilar de la PAC, y orientado a funciones "no productivistas" del medio rural), el FEADER (Fondo Europeo para la Agricultura y el Desarrollo Rural), separado del FEOGA (que pasa a denominarse FEAGA - Fondo Europeo Agrícola de Garantía, para financiar el primer pilar de la PAC, es decir la política de protección de mercados). 
Para los no familiarizados con el tema, esta distribución puede resultar sorprendente. Es, ni más ni menos, la "cristalización" financiera de una serie de prioridades históricas de la construcción europea. Sin duda, con mucho, la agricultura ha sido durante décadas el sector prioritario en la asignación de los recursos comunes de la Unión, seguida de la política de cohesión interterritorial. El papel estelar de la PAC en el presupuesto ha venido suscitando grandes polémicas internas en las últimas décadas provocando en ocasiones crisis graves como la del llamado "cheque británico"10. Es cierto que, en términos porcentuales, la importancia relativa de las ayudas agrarias ha ido disminuyendo paulatinamente mientras aumentaban los fondos estructurales, debido a las sucesivas reformas de la PAC y a la ampliación y mejora de las políticas regionales de compensación o de cohesión.

\subsection{Los saldos netos}

Un ejercicio inevitable al referirse a las contribuciones de los Estados miembros al presupuesto de la UE es el cálculo de los saldos netos presupuestarios, es decir, la diferencia entre los recursos aportados porcada país y las asignaciones recibidas por los diversos conceptos de gasto arriba enumerados. Este tema nos permite abordar brevemente la cuestión de si el sistema presupuestario de la UE es suficientemente equitativo.

Naturalmente, dado el sistema de cálculo de ingresos vigente (porcentaje sobre la base IVA y reparto en proporción a la RNB), los países relativamente más ricos aportan más en términos absolutos que los países menos ricos ${ }^{11}$; por otro lado, los países con más agricultura y/o con menor nivel de desarrollo relativo, reciben más fondos comunitarios, dado que estos son los principales conceptos de gasto. Ello conduce a que, obviamente, hay países contribuyentes netos, que arrojan al final del ejercicio un saldo negativo (pagan más de lo que reciben), y países receptores netos, que tienen saldo positivo (reciben más de lo que pagan). Estamos por tanto ante una especie de "fiscalidad progresiva", aunque no perfectamente progresiva, lo que-dado el sistema-es a todas luces imposible.

Tradicionalmente, el principal contribuyente neto, en términos globales, ha sido siempre Alemania, con una aportación neta total en los últimos años en

10 Véase nota 13 infra.

11 Preferimos reservar el calificativo de "pobres" para los que realmente lo son. 
torno a los 8.000 millones de euros anuales; obviamente, el país más beneficiado es España, que ha recibido en fechas recientes una cifra media total neta situada en torno a los 7.000 millones de euros anuales para el último periodo de programación (2000-2006) $)^{12}$. Sin embargo, como se observa en el gráfico siguiente (con datos de 2003, inmediatamente anteriores a la ampliación al Este), en términos de aportación neta per cápita, los mayores contribuyentes (saldo negativo) han venido siendo últimamente Luxemburgo, Países Bajos y Suecia. Y, de forma correlativa, en términos de saldo neto positivo per cápita, es decir teniendo en cuenta la población, ya no es España el país receptor más beneficiado, sino que la superan tradicionalmente, Irlanda, Portugal y Grecia, por este orden.

\section{GRÁFICO 1}

\section{Saldos netos nacionales (euros per cápita en 2003)}

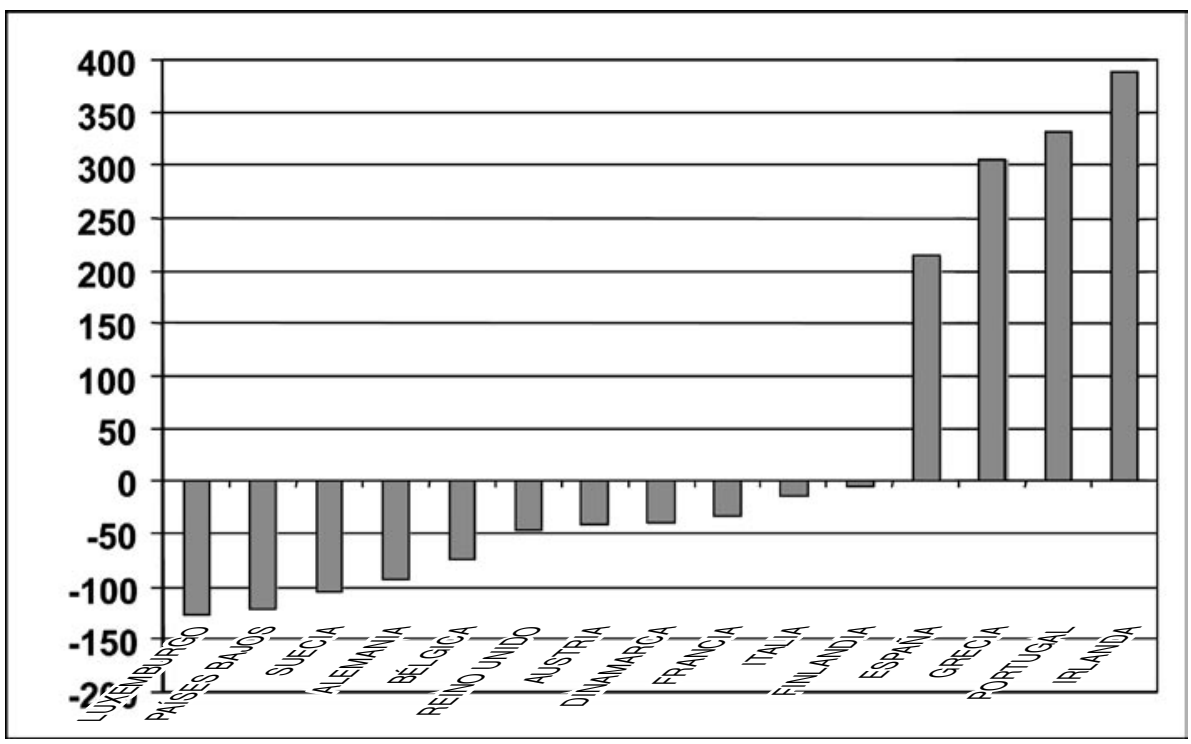

Fuente: Bob TAYLOR (2005), “Europe's World guide to the EU budget negotiations”, Europe's World, autumn, pp. 134-141.

12 A escala regional, Andalucía, por ejemplo, que es -con mucho- la Comunidad Autónoma que más fondos europeos recibe, ha venido obteniendo más de 3.000 millones de euros anuales por los distintos conceptos de ayuda. 
Más riguroso resulta el cálculo del saldo neto expresado en términos de \% sobre la Renta Nacional Bruta del país, porque permite tomar en cuenta no ya la población sino el nivel relativo de renta. En el cuadro siguiente aparecen dichos valores relativos para los 15 países miembros en 2002, una vez contabilizada la devolución al Reino Unido ${ }^{13}$.

\section{CUADRO 1}

Saldos presupuestarios netos después de la corrección británica en la $\mathrm{UE} / 15$ (2002) - En \% de la RNB

\begin{tabular}{|l|c|}
\hline Países Bajos & $-0.51 \%$ \\
\hline Suecia & $-0.29 \%$ \\
\hline Luxemburgo & $-0.25 \%$ \\
\hline Alemania & $-0.24 \%$ \\
\hline Italia & $-0.23 \%$ \\
\hline Reino Unido & $-0.17 \%$ \\
\hline Francia & $-0.14 \%$ \\
\hline Austria & $-0.11 \%$ \\
\hline Bélgica & $-0.10 \%$ \\
\hline Dinamarca & $-0.09 \%$ \\
\hline Finlandia & $0.00 \%$ \\
\hline España & $1.29 \%$ \\
\hline Irlanda & $1.50 \%$ \\
\hline Portugal & $2.14 \%$ \\
\hline Grecia & $2.39 \%$ \\
\hline
\end{tabular}

Fuente: Comisión Europea.

13 En efecto, en los primeros años 80, después de duras negociaciones, Margaret Thatcher consiguió una famosa excepción que consiste en que al Reino Unido se le devuelvan cada año 66 centavos por cada euro de su saldo negativo neto. Esa cantidad es abonada por el resto de los países, pero Alemania, Países Bajos, Suecia y Austria sólo pagan el 25\% de la parte que les corresponde, por ser los mayores contribuyentes netos; en consecuencia, Francia, Italia y España pagan la mayor parte del montante correspondiente a la devolución del "cheque británico". 


\subsection{Las "perspectivas financieras"}

La firma del Acta Única Europea (probablemente el Tratado más ambicioso de la historia de la construcción europea ${ }^{14}$ ), que ponía en marcha el proceso de creación del llamado "Mercado único europeo", pone de manifiesto que no se podía construir un mercado único sin un horizonte presupuestario que permitiera acometer proyectos más allá de una anualidad. Construir el mercado único suponía transformar estructuras y esa transformación estaba limitada por los presupuestos europeos anuales de aquel entonces. El AUE además consagra la política regional como política comunitaria e introduce a la CEE en la senda de lo que hemos denominado "capitalismo renano"15; de hecho las primeras perspectivas financieras (paquete Delors I, por el nombre de su impulsor, el entonces presidente de la Comisión) duplican esta partida a lo largo del periodo; el paquete Delors II vuelve a repetir la duplicación de los fondos estructurales.

Las perspectivas financieras son un esquema de planificación presupuestaria plurianual que establece los límites de gastos de la UE. Es obligatorio, en el sentido de que los "techos" de gasto establecidos por las perspectivas financieras deben ser respetados en el procedimiento presupuestario anual. Además, este mecanismo permite despejar las incertidumbres (e incluso crisis) anuales en torno al presupuesto. Hasta la fecha ha habido tres "paquetes" (como se les conoce) financieros: Delors I (1988-1992), Delors II (1993-1999) y Agenda 2000 (2000-2006). Esta última, aprobada con el horizonte cercano de la ampliación a los países del Este, constituye realmente el principio del declive de la dinámica iniciada por Delors; la Comisión insistía entonces en la necesidad de aumentar el techo presupuestario al 4\% el PNB agregado de la CEE; finalmente no fue así, el techo se congeló.

En efecto, entre los muchos elementos de interés de estos marcos presupuestarios plurianuales se encuentra el techo máximo de recursos puestos a disposición de la UE en términos de \% del PIB comunitario agregado. En el primer "paquete" financiero (Delors I) dicho techo ascendía a 1,12\%; en el segundo periodo (Delors II) ascendió al 1,27\%; según la Agenda 2000, en el periodo 2000-2006 el límite máximo de gasto, incluidas las previsiones para reservas, ascendía al 1,27\% de la Renta Nacional Bruta $(R N B)^{16}$ europea (incluyendo el "margen

14 "L’Acte unique: mon traité favori", expresión usada por Jacques Delors (2004), Mémoire, Paris, Plon, p. 202.

15 Michel Albert (1993), Capitalismo contra capitalismo, Buenos Aires, Paidós.

16 Hasta 2001 se hacía referencia al tope de 1,27\% del PNB; en ese año se produjo un ajuste por cambios estadísticos y se estableció la equivalencia con la RNB. 
para imprevistos"), cifra que, por cierto, nunca se alcanzó, dado el carácter restrictivo de las decisiones presupuestarias anuales tomadas por los Estados miembro. En la práctica no se han superado los topes totales de las perspectivas fijados en 1999 y los créditos de pago han representado poco más del 1\% de la RNB. De hecho, con la Agenda 2000 se congeló el techo presupuestario, se paró el crecimiento de los fondos de la política regional y, aunque ha habido programas específicos pre-adhesión, la UE no ha sido generosa (como sí lo fue cuando entraron España y Portugal) para dotar de recursos a los nuevos Estados miembros, la reforma de la PAC se ralentizó etc. ${ }^{17}$

En este contexto histórico, recientemente, como hemos indicado, han sido aprobadas las nuevas perspectivas financieras para el periodo 2007-2013. Como veremos, desgraciadamente, se trata de una decisión que se sitúa en continuidad con la dinámica introducida por la Agenda 2000.

\section{Las nuevas perspectivas financieras 2007-2013: ¿la muerte de la cohesión? ${ }^{18}$}

\subsection{El origen de la propuesta: el informe Sapir}

La vieja y permanente contestación por parte de algunos Estados miembro a algunos desequilibrios presupuestarios, unida a la persuasión de que era preciso reformar el modelo de financiación, condujo a la Comisión Europea a plantear una propuesta de revisión a fondo del sistema. Para ello, se presentó en 2003 un famoso informe ${ }^{19}$ que lleva el nombre de André Sapir, el economista belga que coordinó los trabajos de la comisión creada al efecto. El texto es mucho

17 Quizá no esté de más recordar que la presidencia de la Comisión que ostentaba por entonces Jacques Santer, no ha sido precisamente de las que pasará a la historia. Como es sabido, dicha Comisión se libró, por muy poco, de un voto de censura en el Parlamento, lo que hubiera constituido un precedente único en el proceso europeo.

18 Título del artículo de Felipe González en El País del 12 de diciembre de 2005, precisamente a propósito de estas cuestiones. Aunque, como hemos indicado, el declive comenzó realmente en la Agenda 2000.

19 Muy expresivamente, el primer ministro británico Tony Blair, en un importante discurso al Parlamento europeo con ocasión del comienzo de la presidencia británica del segundo semestre de 2005 se refirió, entre otras cosas, al informe Sapir en estos términos: "El informe Sapir señala el camino. Publicado por la Comisión Europea en 2003, plantea con claridad y detalladamente cómo debería ser un moderno presupuesto europeo. Pónganlo en práctica. Pero un presupuesto moderno para Europa no puede ser uno que, de aquí a 10 años, siga gastando el 40 por ciento de sus fondos en la PAC." 
más que una propuesta de modificación del sistema presupuestario europeo. La filosofía básica del informe -muy acorde con las nuevas prioridades de la UE en lo que se ha llamado la Agenda de Lisboa ${ }^{20}$, centrada en la competitividad-se puede resumir en las siguientes afirmaciones:

a) El mercado interior debe completarse de modo que pueda desempeñar el papel que le corresponde en la consecución de un objetivo de carácter más general, el desarrollo sostenible, movilizando a tal fin las políticas económicas, sociales y medioambientales. Esta prioridad abarca "la competitividad y la cohesión", así como "la gestión sostenible y la protección de los recursos naturales". Son estos dos últimos campos los que afectan más claramente al presupuesto, yenglobarían (mejorándolas) las actuales partidas de gastos en política regional y agraria, respectivamente.

b) El concepto político de ciudadanía europea se vertebra en torno a la construcción de un espacio de libertad, justicia, seguridad y acceso a los bienes públicos básicos.

c) Porúltimo, Europa debería proyectaruna imagen coherente comosocio aescala mundial, inspirándose en sus valores básicos a la hora de asumir responsabilidades comunes en la escena mundial, promover el desarrollo sostenible y contribuir a la seguridad civil y estratégica. Ello se traduce en algunas partidas presupuestarias como la de ayuda oficial europea al desarrollo.

Precisamente entre las propuestas más radicales del informe se encuentran las relativas a los presupuestos. El informe proponía cambios en el sistema presupuestario europeo que podrían calificarse de revolucionarios. La estructura misma del presupuesto cambiaba pero, sobre todo, se recomendaba repensarlo por completo, desmantelando la $P A C^{21}$ y dirigiendo prioritariamente las ayudas regionales a los nuevos Estados miembro. De alguna manera, lo que se proponía era un "presupuesto base cero", construyendo la matriz de gastos a partir de un planteamiento nuevo de los objetivos y prioridades; era un cambio demasiado drástico. Aun tratándose de un informe encargado por el presidente

20 Se trata de un ambicioso programa de modernización del conjunto de la economía de la UE propuesto en el Consejo Europeo de Lisboa de marzo de 2000; su objetivo esencial era acelerar el ritmo de crecimiento económico de la Unión que se ha quedado rezagado frente al de sus más importantes competidores mundiales, comenzando por Estados Unidos. Sus conclusiones van mucho más allá del problema presupuestario, pero es indudable que en buena parte fue ese tema el que suscitó más controversia e hizo "popular" el documento.

21 En su propuesta el informe reducía drásticamente a un máximo del 15\% el presupuesto para la agricultura. 
de la Comisión, Romano Prodi, los propios comisarios responsables de las dos áreas (PAC y también política regional) se sintieron obligados a expresar su desacuerdo con esas opciones tan radicales.

\subsection{La propuesta de la Comisión}

La Comisión Europea no fue tan lejos como el informe Sapir, pero sí que propuso en 2004 cambios sustanciales en la propia nomenclatura y filosofía de los presupuestos. En particular, avanzó cuatro prioridades para el período 2007-2013: el desarrollo sostenible, la protección de los recursos naturales, los intereses de los ciudadanos y el fortalecimiento de la voz y el peso de la Unión Europea en el foro mundial. En consecuencia modificó-almenosnominalmente-la estructura de los gastos. Compárese, por ejemplo la clasificación de los gastos con los conceptos tradicionales que aparecen en los presupuestos hasta 2006.

\section{CUADRO 2}

\section{Los capítulos de gastos de la Unión Europea. Situación actual y futura}

\begin{tabular}{|c|c|c|c|c|}
\hline $\begin{array}{l}\text { Los conceptos } \\
\text { tradicionales }\end{array}$ & $\begin{array}{c}\% \\
2006\end{array}$ & $\begin{array}{c}\text { Los nuevos conceptos de gasto en } \\
2007-2013 \text { y su equivalencia en el } \\
\text { presupuesto } 2006\end{array}$ & $\begin{array}{c}\% \\
2006\end{array}$ & $\begin{array}{c}\% \\
2013\end{array}$ \\
\hline \begin{tabular}{l|} 
1. Agricultura \\
2. Operaciones \\
$\quad$ estructurales \\
3. Políticas \\
internas \\
4. Acciones \\
$\quad$ externas \\
5. Administración \\
6. Reservas \\
7. Ayudas pre- \\
adhesión \\
8. Compensaciones \\
\end{tabular} & $\begin{array}{r}45,54 \\
31,83 \\
7,94 \\
4,80 \\
5,94 \\
0,41\end{array}$ & $\begin{array}{l}\text { 1. Crecimiento sostenible } \\
\text { 1a. Competitividad en materia de } \\
\text { crecimiento y empleo } \\
\text { 1b. Cohesión en materia de } \\
\text { crecimiento y empleo } \\
\text { 2. Preservación y gestión de los recursos } \\
\text { naturales (incluyendo Agricultura } \\
\text { - Gastos de mercado y pagos directos) } \\
\text { 3. Ciudadanía, libertad, seguridad y } \\
\text { justicia } \\
\text { 4. La UE como interlocutor global } \\
\text { 5. Administración, Compensaciones, etc. }\end{array}$ & $\begin{array}{c}46,4 \% \\
1,9 \% \\
9,3 \% \\
3,8 \% \\
\end{array}$ & $\begin{array}{l}1,6 \% \\
6,3 \% \\
6,0 \% \\
\end{array}$ \\
\hline & $100 \%$ & & $100 \%$ & $100 \%$ \\
\hline
\end{tabular}

Fuente: Comisión Europea. Elaboración propia.

22 Los datos varían ligeramente según las diversas fuentes, debido probablemente a las fechas de elaboración; creemos haber tomado los correspondientes a la versión aprobada en mayo de 2006. La correspondencia con la primera parte del cuadro no puede ser total porque se modifican los contenidos de las partidas de gasto.

23 Se trata de fondos destinados a algunos nuevos Estados miembros para evitar que al comienzo les resulte un saldo neto deficitario. 
No se escapa a nuestros lectores que de algún modo se juega con las palabras $y$ que todos los conceptos anteriores del gasto se incluyen con otro nombre en las nuevas partidas. Pero no cabe duda de que se producen inflexiones en los pesos relativos. La antigua política regional ("operaciones estructurales") se incluye en el epígrafe $1 b$ "Cohesión en materia de crecimiento y empleo". Las ayudas agrarias, incluyendo las destinadas al desarrollo rural, están en el epígrafe 2 "Preservación y gestión de los recursos naturales". Utilizando la nueva nomenclatura la tabla anterior permite apreciar los cambios que se producirán en la asignación de gastos entre 2006 y 2013. Lo más significativo es: a) el cambio de filosofía, proponiendo que este presupuesto (a nuestro juicio demasiado exiguo) se oriente a favor del crecimiento de la competitividad ${ }^{24}$, b) la disminución clara, aunque lenta, del peso relativo de las ayudas agrarias, y c) el aumento de los fondos regionales ${ }^{25}$.

No desaparecen, por tanto, ni la PAC ni la política regional pero, de alguna manera, se anuncian cambios más drásticos que, con toda seguridad, se producirán a partir de 2013.

Por otro lado, la Comisión presentó una propuesta sobre modificación del sistema de financiación, o sea, del sistema de ingresos, con varias hipótesis. Sólo las enunciamos: a) mantenimiento del actual sistema; obviamente es una solución poco satisfactoria; b) sistema de financiación basado exclusivamente -aparte de los recursos propios procedentes de los aranceles comunes- en la $R N B$, dado que actualmente la mayoría de los recursos proceden de esta fuente, ¿por qué no generalizarla, eliminando el IVA como base de cálculo?; c) sistema de financiación basado en un impuesto real sobre el consumo energético; d) sistema basado en una parte del IVA efectivamente pagado por los ciudadanos; e) la última hipótesis consistiría en un sistema basado en una parte del impuesto de sociedades. Para las tres últimas hipótesis se avanza el argumento de que los ciudadanos deberían sentir de forma personal y directa que "la UE la pagan de su bolsillo". Naturalmente, la Comisión calculó los escenarios derivados de los diferentes sistemas. Sin embargo, el acuerdoalcanzado mantiene el sistema actual (con algunos matices) y prevé la entrada en vigor de un nuevo sistema, quizás alguno de los propuestos por la Comisión, pero aún no definido, a principios de 2009. Los cambios que sí comenzarán a principios de 2007 son los siguientes:

24 "Reorientar la inversión hacia el crecimiento y el empleo" reza el título sobre estos datos en algunos documentos oficiales de la Comisión.

25 Hemos considerado la estructura de gastos definitivamente aprobada, tal como se explica algo más adelante. 
a) la tasa aplicada a la base imponible del IVA se fija en 0,3\% (frente al $0,5 \%$ actual);

b) para el periodo 2007-2013 solamente, se modifica la tasa de los siguientes países: Austria 0,225\%, Alemania 0,15\%, Países Bajos y Suecia 0,10\%;

c) durante el periodo 2007-2013 solamente, los Países Bajos se beneficiarán de una reducción de 605 millones de euros de su contribución en la parte procedente de la Renta Nacional Bruta y Suecia de 150 millones de euros.

Por último, la propia Comisión ha presentado también una propuesta para corregir desequilibrios netos negativos y prolongados que perjudiquen a algún país; de esa forma, el llamado "cheque británico", dejará de ser una excepción. La propuesta de la Comisión va en la línea de corregir esos desequilibrios teniendo en cuenta "la magnitud del desequilibrio presupuestario ("excesivo") y la riqueza de un Estado miembro comparada con el conjunto de la UE ("prosperidad relativa")". Dicho sistema "de corrección", hasta ahora sólo aplicado al Reino Unido, se extenderá en el próximo periodo de programación a todos los Estados miembros que tengan contribuciones excesivas, es decir más del 0,35\% de la Renta Nacional Bruta del país, con ciertos límites totales ${ }^{26}$. Naturalmente, el resto de países deberán abonar, en proporción a su renta, las cantidades así rebajadas a los mayores contribuyentes netos.

\subsection{Negociaciones y acuerdo final}

A lo largo del primer semestre de 2005 (turno semestral de presidencia luxemburguesa), del segundo semestre del mismo año (presidencia británica) y del primer semestre de 2006 (austriaca), se desarrolló el debate acerca de las propuestas de la Comisión. Hubo una propuesta intermedia, que corregía la de la Comisión, elaborada por la presidencia luxemburguesa, pero no consiguió el consenso necesario. Durante el segundo semestre de 2005 parecía imposible

26 Llevando hasta el final la lógica del razonamiento ello debería conducir a que el saldo neto final de cada país fuera inversamente proporcional a su nivel relativo de renta: a mayor nivel de renta, mayor saldo neto negativo presupuestario, con lo que la jerarquización de los contribuyentes netos iría de mayor a menor nivel de renta relativa. En todo caso, para el próximo periodo seguirá vigente el "cheque británico" con algunos matices; se trata de un tema polémico pendiente de mucha discusión. Véanse; a) el documento correspondiente citado en la nota 15 supra; b) el acuerdo final alcanzado el 4 de abril y ratificado por el Consejo el 15 de mayo de 2006. 
llegar a un acuerdo pero, gracias a la presión de Angela Merkel, recién elegida canciller en las elecciones alemanas del 22 de noviembre de 2005, se consiguió el primer consenso entre los 25 en la cumbre europea de diciembre de 2005. La propuesta pasó luego a discusión del Parlamento Europeo, que anteriormente había aprobado el 8 de junio de 2005 otra propuesta, conocida como el informe Reimer Böge (por el parlamentario que la encabezó); en aplicación de sus competencias, el Parlamento introdujo modificaciones al texto aprobado en el Consejo Europeo de diciembre de 2005. Por fin, como ya indicamos, el acuerdo interinstitucional definitivo Consejo-Parlamento tuvo lugar el 17 de mayo de 2006. De hecho, las diferencias entre las distintas propuestas son escasas; el sistema, nada satisfactorio, consiste en hacer pequeñas concesiones a unos y otros para lograr el acuerdo de todos los miembros.

Tras dicho acuerdo final Consejo-Parlamento, el marco financiero adoptado, que presentamos resumido en el cuadro siguiente, constituye una adaptación, rebajada, de la primitiva propuesta de la Comisión. Estas son las cifras totales:

CUADRO 3. Perspectivas financieras de la UE para el periodo 2007-2013, según el acuerdo interinstitucional (Consejo de Ministros, Parlamento, Comisión) firmado el 17 de mayo de 2006

\begin{tabular}{|l|r|r|}
\hline \multicolumn{1}{|c|}{ Concepto } & \multicolumn{1}{|c|}{$\begin{array}{c}\text { Millones } \\
\text { de euros } \\
\mathbf{2 0 0 7 - 2 0 1 3}\end{array}$} & \multicolumn{1}{|c|}{$\begin{array}{c}\text { \% del } \\
\text { total }\end{array}$} \\
\hline 1.Crecimiento sostenible & 382.139 & 44,2 \\
\hline $\begin{array}{l}\text { la. Competitividad en materia de crecimiento y } \\
\text { empleo }\end{array}$ & 74.098 & 8,6 \\
\hline 1b. Cohesión en materia de crecimiento y empleo & 308.041 & 35,6 \\
\hline $\begin{array}{l}\text { 2. Preservación y gestión de los recursos } \\
\text { naturales }\end{array}$ & 371.344 & 43,0 \\
\hline $\begin{array}{l}\text { (incluyendo únicamente Agricultura y Gastos de } \\
\text { mercado y pagos directos) }\end{array}$ & 293.105 & 33,9 \\
\hline 3. Ciudadanía, libertad, seguridad y justicia & 10.770 & 1,2 \\
\hline 4. La UE como interlocutor global & 49.463 & 5,7 \\
\hline 5. Administración & 49.800 & 5,8 \\
\hline 6. Compensaciones & 800 & 0,1 \\
\hline Total & $\mathbf{8 6 4 . 3 1 6}$ & $\mathbf{1 0 0 , 0}$ \\
\hline
\end{tabular}

Fuente: European Commission (2006) Interinstitutional Agreement on Budgetary Discipline and Sound Financial Management 2007-2013. Référence: MEMO/06/204, 17/05/2006. 
Al final, y después de años de discusiones, el resultado es que el techo presupuestario máximo ha sido rebajado al 1,24\% de la Renta Nacional Bruta (RNB) comunitaria agregada, 0,03 puntos menos que el anterior. La diferencia con la propuesta inicial de la Comisión no es muy grande, pero sí significativa; la Comisión-forzada por el Consejo-proponía un techo de 1,24\% de la RNB agregada, reservando un máximo del 0,10\% para reservas, lo que se traducía en una posibilidad real de gasto del 1,14\% de la RNB; la decisión del Consejo de diciembre de 2005, mantiene el techo máximo del 1,24\% pero dispone para reservas de hasta un $0,24 \%$ de la $R N B$ total dando por supuesto que el gasto efectivo no superará el tope del 1\% que se venía aplicando en el último marco presupuestario plurianual (2000-2006).

\section{Las razones de la polémica presupuestaria}

¿Por qué ha costado tanto llegar un acuerdo y por qué el resultado es insatisfactorio? Sintetizando, en aras de la claridad y aun a riesgo de repetirnos, enumeramos cinco factores que han dificultado notablemente el proceso de negociación y que se entremezclan en los debates: a) un cierto hartazgo de los países que tradicionalmente son contribuyentes netos, algunos de los cuales conocen dificultades considerables para cuadrar sus presupuestos públicos internos; b) el esfuerzo financiero adicional en las políticas de solidaridad y cohesión que sería necesario tras la adhesión a la Unión Europea de países con un nivel de desarrollo relativo muy inferior a la media de la UE-15; c) las pérdidas relativas que implica esta situación para los países que, hasta ahora, habían sido los principales receptores de fondos estructurales y de cohesión; d) las dudas de algunos gobiernos sobre la "eficiencia" de ciertos gastos, sobre todo los relacionados con la Política Agraria Común; y, relacionado con lo anterior, e) los recelos por la desigual distribución de los costes del presupuesto en general y de los gastos de la ampliación en particular, con especial referencia a la excepcionalidad del cheque británico. Veamos brevemente estos cinco factores por ese mismo orden.

4.1. "Ganadores y perdedores": países contribuyentes netos frente a receptores netos

Ante todo, los gobiernos se presentan en los Consejos dedicados a este tema "con la calculadora en la mano": todos quieren poder trasladar a sus respectivos países la idea de que, al menos, no han salido perjudicados en la negociación. 
En todo caso, hablar de ganadores y perdedores es difícil, cuando se ha llegado a un resultado fruto de equilibrios más o menos razonables. Haciendo balance, para el periodo próximo de programación, según una simulación presentada por la Comisión, con el nuevo sistema de corrección o devolución parcial (que afecta a más países, además del Reino Unido), los datos son los que aparecen en el cuadro 4. En este caso se contabilizan a favor de Bélgica y Luxemburgo los gastos derivados de las instituciones comunitarias ubicadas en su mayoría en esos países; hasta ahora esos gastos no se computaban en lo que percibían esos países.

\section{CUADRO 4. Saldo neto presupuestario según estimaciones de la Comi- sión Europea (media del periodo 2008-2013) ${ }^{27}$ - En \% de la RNB}

\begin{tabular}{|l|c|}
\hline $\begin{array}{c}\text { Países } \\
\text { receptores netos }\end{array}$ & $\begin{array}{c}\text { \% de la } \\
\text { RNB }\end{array}$ \\
\hline Luxemburgo & 5,83 \\
\hline Letonia & 4,44 \\
\hline Lituania & 4,43 \\
\hline Polonia & 3,79 \\
\hline Estonia & 3,78 \\
\hline Eslovaquia & 3,30 \\
\hline República Checa & 3,20 \\
\hline Hungría & 3,09 \\
\hline Grecia & 2,19 \\
\hline Portugal & 1,53 \\
\hline Eslovenia & 1,33 \\
\hline Bélgica & 1,26 \\
\hline Malta & 1,09 \\
\hline Irlanda & 0,50 \\
\hline España & 0,25 \\
\hline
\end{tabular}

\begin{tabular}{|l|c|}
\hline $\begin{array}{c}\text { Países } \\
\text { contribuyentes netos }\end{array}$ & $\begin{array}{c}\text { \% de la } \\
\text { RNB }\end{array}$ \\
\hline Países Bajos & $-0,50 \%$ \\
\hline Alemania & $-0,49 \%$ \\
\hline Suecia & $-0,46 \%$ \\
\hline Reino Unido & $-0,46 \%$ \\
\hline Austria & $-0,41 \%$ \\
\hline Italia & $-0,36 \%$ \\
\hline Francia & $-0,34 \%$ \\
\hline Chipre & $-0,34 \%$ \\
\hline Dinamarca & $-0,26 \%$ \\
\hline Finlandia & $-0,20 \%$ \\
\hline
\end{tabular}

Fuente: Comisión Europea, tomado de Taylor, op.cit. cfr. Gráfico 1, supra, p. 146

27 La fuente utilizada se refiere a este periodo y no al 2007-2013 como hubiera sido más lógico. Probablemente ello se debe a que 2007 será un año transitorio para las modificaciones previstas en el sistema. 
Según estos cálculos, para España, por ejemplo, los cambios que se avecinan significarían el paso de un balance neto favorable del 1,2-1,3\% del PIB en el periodo 2000-2006 a un balance neto de sólo 0,25\% como media de este periodo 2008-2013.

Refiriéndonos a los países mayores contribuyentes netos, la pretensión de acabar con sus saldos negativos, llevada al absurdo, equivaldría a que todos los países retiraran la misma cantidad de fondos que aportan, lo cual quitaría todo sentido al presupuesto común e iría contra su filosofía misma y la de la propia construcción europea, entendida-entre otras cosas-como un espacio de solidaridad supranacional que va mucho más allá de la abolición de fronteras y la unificación de mercados.

Sin embargo, hay que comprender las razones de lo que hemos denominado "tacañería" de los Estados miembros más ricos a la hora de aportar recursos al presupuesto comunitario. Razones políticas y económicas están en la base de esas actitudes. El paradigma de la argumentación económica es el Reino Unido cuyo líder, laborista, no deja de ser ante todo británico, por lo que ve con malos ojos los gastos comunes, en particular los derivados de la Política Agraria. Por su parte, Alemania y Francia tienen serios problemas de crecimiento económico y muchas dificultades a la hora de equilibrar sus presupuestos públicos, hasta el punto de no llegar a cumplir en los últimos años los compromisos incluidos en el llamado Pacto de Estabilidad que obliga a los miembros de la zona euro.

4.2. La necesidad de un mayor esfuerzo de solidaridad hacia los nuevos Estados miembros

El debate ha estado también muy marcado por la insistencia de algunos países, por ejemplo Alemania y Reino Unido, en la necesidad de reorientar los fondos hacia la mejora de la convergencia de la mayoría de los nuevos Estados miembros. A este respecto, conviene diferenciar nítidamente el principio de cohesión que inspira a la Unión Europea, que es un valor indiscutible del modelo, y que supone transferencia de recursos desde las regiones o países más ricos a los menos desarrollados, de los destinos concretos que se da a esos recursos (como los gastos de la PAC por citar el más polémico) que pueden ser discutidos. Lo primero constituye una característica del llamado "modelo renano" (frente al modelo anglosajón, de tendencia más explícitamente neoliberal), que no es más que expresión a escala europea de lo que ha supuesto en cada país miembro la instauración del llamado "Estado social". 
Conviene recordar aquí que, al inicio de la integración europea, la política regional era inexistente. El Tratado de Roma ni siquiera la contempla y hubo que esperar a 1973, con la primera ampliación de la Comunidad (Reino Unido, Irlanda y Dinamarca) para que se creara el Fondo Europeo de Desarrollo Regional (FEDER), instrumento principal de la política regional. Cuando se produjo la adhesión de España y Portugal, países con niveles de renta muy inferiores a los entonces 10 Estados miembro, se produjo un gran incremento de los fondos destinados a dicha política, que prácticamente se duplicaron. Esa tendencia histórica se rompe con las decisiones tomadas para el periodo 2007-2013. Hubiera sido precisa una mayor dosis de "europeísmo" y una capacidad de liderazgo y de convicción de los que hoy carecen los dirigentes nacionales y las propias autoridades comunitarias.

Siendo la solidaridad interterritorial y supranacional una de las claves del éxito de la construcción europea, pensamos que hay que defender a toda costa su mantenimiento. Renunciar a ella sería traicionar un componente esencial del acervo histórico comunitario. Como ya hemos indicado, las "cuentas" europeas no parecen avanzar en la dirección correcta.

\subsection{El perjuicio para los países más beneficiados en la UE-15}

La ampliación de 2004 a 10 nuevos países miembros, la mayoría de ellos con un nivel relativo de renta muy inferior a la media europea, implica que casi todos serán necesariamente receptores netos de fondos comunitarios. Ahora bien, si el marco presupuestario aprobado "congela" de alguna manera los gastos comunitarios, la conclusión inmediata es obvia. Al rebajar el techo global de recursos disponibles (incluso si se hubiera mantenido o subido ligeramente) la "factura" de la ampliación habrá de ser pagada de una de estas dos maneras: a) o los países habituales contribuyentes netos, encabezados por Alemania, aportan más fondos al presupuesto común; b) o los países de la antigua UE-15 que eran receptores netos dejarán de serlo en todo o en parte. Dado que en la discusión presupuestaria no se ha aceptado la primera alternativa, queda claro que de hecho se producirá un trasvase de los recursos de los países menos prósperos de la antigua UE-15 hacia los países menos desarrollados de la nueva UE-25 y, próximamente, UE-27. Lo cual no deja de ser una consecuencia perversa de la evolución del sistema. Como escribió acertadamente Felipe González unos días antes de la cumbre en que se aprobaron las perspectivas financieras: 
“...la financiación de la cohesión para los más pobres de la Unión a 25 saldría de los que tienen menos nivel de renta del grupo de los antiguos socios. Los menos desarrollados de ayer ayudan a los aún menos desarrollados de hoy, en tanto los más desarrollados de antes y de ahora se quedan como estaban." 28

\subsection{La crisis de legitimidad de la $\mathrm{PAC}^{29}$}

En los debates presupuestarios, desde hace más de 20 años (no es, por tanto, un asunto coyuntural), un tema recurrente consiste en la crítica de los gobiernos de algunos países al excesivo gasto agrario de la UE. Se trata de un debate bien diferente al relativo al mantenimiento del modelo europeo de solidaridad supranacional, pero que explica en buena parte la insistencia de algunos países (Gran Bretaña es su principal abanderado) para que se reduzca en un futuro el gran volumen de fondos destinado a la protección agraria.

Por su parte, la PAC, inserta en el Tratado de Roma, representó sin duda en los orígenes de la Comunidad Económica Europea la expresión de la solidaridad intersectorial. Eran unas décadas donde la protección agraria se justificaba más que ahora, y la PAC constituía de hecho la concesión de Alemania a Francia por la creación de un Mercado Común Europeo que no sólo favorecía el desarrollo de un potente sector industrial, sino que pasaba página sobre la ruptura trágica que había supuesto la segunda contienda mundial. De hecho, además, la PAC sirvió para crear "conciencia europea" puesto que durante casi dos decenios constituyó la única política de solidaridad supranacional de la Comunidad Europea. Sin embargo, como tal política está hoy muy cuestionada, tanto por razones internas como externas y no puede aceptarse que la suerte de las políticas de solidaridad europeas tengan por qué estar indisolublemente unidas a la PAC. Es esta crisis de legitimidad la que ha provocado las sucesivas (e incompletas) reformas, arrancadas no sin dificultades a los países más beneficiados por las ayudas de la PAC, con Francia a la cabeza. Y ese déficit de legitimidad explica también que el texto aprobado deje planteada, aunque la aplace a 2008-2009, la necesidad de una reforma más a fondo del sistema de gastos.

28 "La muerte de la cohesión europea", El País, 12 de diciembre de 2005.

29 Véase nuestra reflexión editorial: Consejo de Redacción (2001), "La Política Agraria Común europea en un mundo globalizado". Revista de Fomento Social, n 223, julio-septiembre, pp. 343-367. A pesar de las reformas posteriores, las ideas de fondo de aquel texto siguen estando vigentes. 
En todo caso, si disminuyen las partidas destinadas a la protección de los mercados agrarios, habría que luchar para que, a fin de cuentas, no se produzca una reducción de las aportaciones en el mismo montante que se vayan reduciendo dichos fondos. Sería preciso mantener las aportaciones pero enfocar de otro modo el destino de esos recursos. El hecho de que, en las propuestas de "previsiones presupuestarias", el \% del equivalente a los antiguos fondos estructurales aumente, parece abonar la idea que el principio de cohesión no se cuestiona.

\subsection{Los recelos antes la excepcionalidad del "cheque británico"}

Ya hemos explicado el origen histórico y la justificación del reembolso que ha venido recibiendo el Reino Unido desde hace 20 años y que está directamente relacionados con su permanente contestación a la PAC, a la que acabamos de referirnos. El "cheque británico" no es una arbitrariedad en la medida en que realmente, durante años, los británicos eran los mayores contribuyentes netos en términos de \% de su RNB. Dado que la solución lógica que hubiera consistido en replantear los gastos agrarios no iba a recibir el aval unánime, y dada la capacidad política y negociadora de la primera ministra Margaret Thatcher, se tomó una decisión bajo presión, que luego no ha sido posible cambiar por la necesidad de disponer de la unanimidad. Y la excepción se ha convertido en regla.

Se comprende, pues, que los países mayores contribuyentes netos (Alemania, Países Bajos, Suecia y Austria) hayan exigido y obtenido, en este debate de las perspectivas financieras 2007-2013, un tratamiento similar al del Reino Unido $^{30}$. Con lo cual se ha llegado a una solución, que resumíamos en el apartado anterior, en la línea de "café para todos". Ésta no puede ser la fórmula del futuro. Habrá que llegar a un consenso sobre la estructura de los gastos y proceder a una reasignación de las contribuciones de la manera más equitativa posible. Hay alternativas: algunas aparecen sugeridas en el apartado conclusivo siguiente.

30 En justicia hay que indicar que, en la "letra pequeña del acuerdo", el gobierno británico ha renunciado a algunos montantes incluidos en su reembolso. A pesar de eso el primer ministro británico Tony Blair ha afirmado su satisfacción: “...por primera vez desde que somos miembros de la UE, el Reino Unido pagará más o menos los mismo que Francia e Italia" (Discurso al Parlamento Europeo, junio 2005). 


\section{Conclusión: algo más que finanzas}

Hasta aquí hemos intentado sintetizar los aspectos técnicos más relevantes del tema que nos ocupa (apartados 2 y 3) y las razones de su dificultad y conflictividad (apartado 4). Confiamos que ello proporcione a nuestros lectores no pocos elementos de juicio. Es hora de concluir con algunas breves valoraciones.

\subsection{Hay alternativas}

¿Existen alternativas? Hay varias. Una de ellas-propuesta porFelipe González en el artículo citado-podría ser que cada país aporte lo que le corresponda en función de su producto por habitante. Se trataría de unos ingresos proporcionales a la renta relativa de los países, sin ninguna progresividad. Es decir, los ingresos se estimarían mediante un porcentaje sobre dicha renta idéntico para todos los países; no se regirían por criterios de progresividad y, por tanto, no cumplirían con el pilar básico de la cohesión. A partir de este ejercicio se pueden discutir con más consistencia las políticas de gasto de la Unión, aplicando, ahí sí, criterios de cohesión, o sea, progresividad. De esa forma ningún país podría cuestionar el volumen de su aportación. Otra posibilidad consistiría en dejar el presupuesto tal como estaba con 15 miembros, añadiendo las cantidades necesarias para aplicar a los nuevos Estados los criterios de cohesión. En ambos casos estamos ante propuestas difíciles de aceptar en el actual escenario de discusión de los gobiernos europeos.

Otra cuestión es lo que va a ocurrir con España. Es comprensible, como indicamos más arriba, que en una UE ampliada, nuestro país haya pasado de ser uno de los de menos renta relativa a aproximarse mucho a la media comunitaria; consecuentemente a medio plazo estamos llamados a dejar de percibir una parte muy importante de los fondos que hasta ahora nos correspondían. Que dicho cambio no sea sólo resultado del llamado "efecto estadístico" (como entran otros "menos ricos", nosotros somos "más ricos"...) sino que corresponda a la evolución de un país desarrollado que aspira a no depender en tan gran medida de los subsidios comunitarios, es un reto que-tarde o temprano-tendremos que afrontar.

\subsection{Si queremos "más Europa" hace falta "más presupuesto"}

Como indicábamos al comienzo de este editorial, la financiación europea no está a la altura, para empezar, de un proyecto del calado del proyecto 
europeo. Las decisiones tomadas en la Agenda 2000, como indicábamos más arriba, marcan el cambio de tendencia que habían introducido los "paquetes" financieros promovidos en la etapa de Jacques Delors como presidente de la Comisión, con los líderes de varios países impulsando en ese sentido (Kohl, González, Miterrand...). Por eso, desde el año 2000, la financiación europea está también muy lejos de la ambición que animaba a los padres de Europa, y desde luego, de la inspiración política que puso en marcha el proceso -actualmente en cuestión- de elaboración y ratificación de la llamada Constitución europea. Hubiera sido un sinsentido ratificar sin problemas la Constitución y quedarnos con un presupuesto tan restrictivo.

No hay más que comparar la magnitud del presupuesto de la UE con el total del presupuesto federal norteamericano que es superior al 15\% de su PIB. Curiosamente en esta Europa que quiere unirse, la descentralización es una tendencia, mientras que los norteamericanos llevan centralizando su gasto desde la década de los cincuenta y, en la actualidad, está en torno al 50\%. No estamos en contra de la descentralización, pero no deja de sorprender el sentido tan opuesto de la evolución en estos dos ámbitos.

\subsection{Crisis de identidad europea en la lucha por la competitividad}

En el fondo, ambas crisis, la de la Constitución y la de las perspectivas financieras, son como las dos caras de la misma moneda: la de una aparente crisis de crecimiento del modelo europeo. Con audacia, y con una fuerte dosis de generosidad, la ampliación de 2005, de 15 a 25 países, supuso un salto cualitativo, no sólo cuantitativo. Pero el "frenazo" sufrido a la hora de poner los medios para que el modelo tenga futuro pone en cuestión el proceso mismo. Sin olvidar que sigue abierto el gran interrogante de dónde se sitúan los límites geográficos de la Unión. Podemos aplicar a los presupuestos las mismas reflexiones que Habermas hace a propósito del proyecto de Constitución:

\footnotetext{
..."el debate acerca de la nueva Constitución ha puesto en el orden del día la cuestión, silenciada y no resuelta, de la "finalidad" del proceso de unificación. Esta espinosa cuestión del telos de toda la empresa tiene dos aspectos. Por un lado, está la cuestión de la estructura política de la comunidad: ¿qué Europa queremos? Y, por otro lado, la cuestión de la identidad geográfica: ¿por dónde pasan las fronteras definitivas de la Unión Europea? El proyecto constitucional deja abiertas ambas preguntas"31.
}

31 Jürgen Habermas (2006), El occidente escindido, Madrid, Trotta, p.75 
Ciertamente, no podemos negar la razón del citado informe Sapir, cuando pone el énfasis en la competitividad. Quizás por primera vez (y esto es algo que aún no han terminado de comprender los ciudadanos franceses), Europa cae en la cuenta de que es una economía postindustrial que necesita materias primas esenciales para mantenersu alto nivel de bienestar. Unas materias primas que no tiene en su territorio y que sólo puede obtener mediante el comercio (igual que el Japón actual). Por ello ha de ser competitiva: una competitividad que sólo se puede alcanzar si mantiene su ventaja tecnológica. El énfasis, que se hace en el informe y en la Agenda de Lisboa, en las nuevas tecnologías se fundamenta en la evidencia empírica de que casi un $40 \%$ del crecimiento norteamericano de los noventa ha estado basado en la incorporación de nuevas tecnologías a los procesos productivos. Una incorporación que ha generado empleo y crecimiento de la productividad. Dicho de otra forma, Europa podría crecer entre un 1,5\% y un $2 \%$ más de lo que hace ahora si hubiera una apuesta decidida por las nuevas tecnologías.

Ese esfuerzo por la competitividad ¿debe significar el abandono del modelo social europeo? Es esta una pregunta de gran calado que se plantea nuestro continente con un cierto nivel de ansiedad. Suscribimos plenamente el siguiente aserto de Jacques Delors refiriéndose a la moneda única:

\begin{abstract}
"Ahora hace falta conciliar las limitaciones que impone la Unión Económica y Monetaria con la continuación de la cohesión económica y social, y la combinación entre cooperación, competitividad y solidaridad que ha sido siempre la clave de todos los avances" 32 .
\end{abstract}

Ciertamente es más fácil decirlo que lograrlo. Pero si el sentido de la evolución europea tuviera que significar la pérdida o el retroceso del espíritu solidario europeo, por una especie de concesión a los modelos más neoliberales hoy al uso, y en aras de una mayor competitividad, habríamos dado un importante paso atrás. En nuestra opinión, estos presupuestos y sus contradicciones son sólo el reflejo de la crisis de identidad, de ideología y de sentido que está viviendo la construcción europea. No sabemos dónde estamos, ni lo que queremos en el mundo del siglo XXI. Y no lo sabemos porque no tenemos un discurso elaborado, que llegue a los ciudadanos, sobre qué significa ser europeo, ni por qué serlo. $Y$, desde luego, no tenemos políticos, ni ideólogos, que sean capaces de teorizar sobre el "europeísmo". De alguna manera, estamos dejando a las fuerzas "nacionalistas", que han sido la raíz ideológica de la mayoría de nuestros desencuentros, la construcción de nuestro futuro.

32 Entrevista, en El País del 8-4-98. 
5.4. Construyendo ciudadanía europea: "de arriba abajo y de abajo arriba"

En la base de todo está el déficit, tantas veces señalado, de una realidad de la identidad de la ciudadanía europea. Por eso se arguye con frecuencia que habría que dar prioridad al enfoque ascendente, de forma que sea la sociedad civil europea quien vaya construyendo el modelo de integración deseado. Y, sin embargo, la historia del proceso demuestra que los avances se han ido produciendo por la iniciativa de gobernantes con visión y con audacia. En este sentido, habrá que superar un enfoque dual y maniqueo: de arriba-abajo, de abajo-arriba. Son necesarias las dos direcciones.

Seguramente uno de los defectos de la gestión política de la Unión es el abuso de la idea de subsidiariedad, sin duda necesaria, pero (mal) entendida como otorgar a lo supranacional "las menos competencias posibles". Esto se ha exagerado tanto que la UE es un ente virtual desde un punto de vista administrativo. Por ejemplo, ¿no debería la UE tener en todas las ciudades importantes un edificio administrativo con su bandera y un administrador de otro país que sea el representante de todo el conjunto ante la ciudadanía, un representante con actividad y participación en la vida pública? Se visualizaría así la existencia de la Unión. Es cierto que eso no parece ir en el sentido centrífugo dominante en los procesos de afirmación identitaria en el propio ámbito español. Pero, de la misma forma, también es importante que la construcción europea se haga desde los ciudadanos, empezando por el tema clave de la educación y por el fomento de asociaciones transfronterizas.

Es hora de terminar. En el frontispicio del primer anteproyecto de la Comisión sobre esta materia ${ }^{33}$, haciendo por cierto una concesión a la lírica, nada frecuente en este tipo de documentos marcadamente tecnocráticos, nos encontramos con la siguiente cita de Antoine de Saint-Exupéry: «En lo que respecta al futuro, nuestra tarea no es predecirlo, sino hacerlo posible.»

A la altura en que nos encontramos, y a la luz de las consideraciones precedentes, una conclusión se impone: la UE no está haciendo posible su futuro.

33 Véase la citada Propuesta provisional de la Comisión Europea (2004), Construir nuestro futuro común, cfr. nota 14 , supra. 